\title{
THE EFFECT OF CARBIMAZOLE ON OXIDATIVE STRESS IN HYPERTHYROID PATIENTS
}

\author{
Maes Muzahim Kassim ALKhyatt ${ }^{1}$, Kassim Salih Abdullah Al Neaimy ${ }^{2 *}$ \\ 1. Department of Pharmacology, College of Pharmacy, University of Mosul, City of Mosul, Iraq. \\ 2. Department of Pharmacology, College of Medicine, University of Mosul, City of Mosul, Iraq.
}

\section{Corresponding author: Maes Muzahim Kassim ALKhyatt}

Email: abdullahkassim@yahoo.com

\section{ORCID}

\section{ABSTRACT}

There is effect of Carbimazole on oxidative stress with Hyperthyroidism. To assess the oxidative stress and total antioxidant capacity in hyperthyroid patient and evaluate the effect of Carbimazole on oxidative stress and total antioxidant status. Case series study design. The study was conducted in departments of general surgery outpatient private clinic of and AL-Jumhori teaching hospital. The study period between Dec .1st, 2020 and April.1st, 2021. Thirty patients newly diagnosed with hyperthyroidism and thirty healthy volunteers as control group were participated in the study. Malondialdehyde (MDA) and total antioxidant status (T-AOC) were measured control group and also measured in patients with hyperthyroidism before and after taking Carbimazole therapy for two months duration. Indicated an increase in mean serum MDA level $(4.74 \pm 3.62 \mathrm{ng} / \mathrm{ml})$, also there was a significantly lower level of T-AOC $(6.72 \pm 3.08$ $\mathrm{U} / \mathrm{ml})$ in patients with HTH disorder before therapy in comparison with the control group $(1.83 \pm 0.47 \mathrm{ng} / \mathrm{ml})$, $(10.38$ $\pm 2.32 \mathrm{U} / \mathrm{ml}$ ), respectively. After two months of antithyroid therapy (Carbimazole), there was a significant reduction in MDA levels $(2.51 \pm 1.99 \mathrm{ng} / \mathrm{ml}),(P$-value $=0.001)$ and a significant increase in serum $T$-AOC level $(8.57 \pm 3.09 \mathrm{U} / \mathrm{ml})$, $(P$-value $=0.001)$ in comparison to their values before therapy. The present study demonstrated that hyperthyroid patients have increased level of malondialdehyde and decreased levels of total antioxidants capacity than the control group while hyperthyroid patients treated with Carbimazole for two months have decreased level of MDA and increased levels of T-AOC than their levels before treatment. This result may give a new insight that Carbimazole may exhibit its effect in the management of hyperthyroidism by acting as an antioxidant.

Keywords: hyperthyroidism, Oxidative Stress, Carbimazole

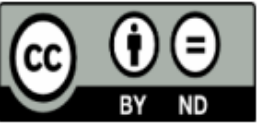

This work is licensed under a Creative Commons Attribution Non-Commercial 4.0 International License.

Received: 30 August 2021, Accepted: 19 October 2021, Available online: 20 January 2022 


\section{INTRODUCTION}

Hyperthyroidism is a state of reduced thyroid stimulating hormone (TSH) concentration and where there is an increase in the secretion of thyroid hormone triiodothyronine (T3) and tetraiodothyronine (T4) by thyroid gland, which are involved in maintaining various metabolism cycles, and (Costilla et al., 2019 ).

Thyroid hormones are the most important factors involved in oxidative metabolism( Joshi et al., 2018). Thyroid hormones synthesis includes a radical intermediate, creating a need for a ROS reaction as part of the organ's function to maintain homeostasis. lodination of tyrosine residues, catalyzed by a peroxidase enzyme, occurs on the endoplasmic reticulum of the thyroid gland cells ( Carrasco ,2005).

Oxidative stress (OS) is defined as an unbalance between the production of prooxidant substances and antioxidant defenses. Thyroid tissue has been found to have high levels of oxidative stress, which has been linked to hyperthyroidism (Mancini et al.,2016).

Increased oxygen demand, mitochondrial respiratory chain malfunction, high intracellular ATP consumption, and increased ROS generation are all linked to hyperthyroidism. Furthermore, there is evidence that oxidative processes have a role in the development of Graves' disease (GD), hyperthyroidism-related damage like thyrotoxic myopathy and cardiomyopathy, and Graves' orbitopathy (Marcocci et al., 2012).

Overproduction and/or inadequate elimination of reactive oxygen species causes oxidative stress, which is a harmful process that plays a key part in the etiology of thyroid dysfunction and consequences (Storz,2005).

If these reactive oxygen species are not removed by required systems, they are harmful to cellular membranes and cause lipid peroxidation (Olia, 2019).

Thyroid hormones are also involved in the synthesis and degradation of non-enzymatic antioxidants such glutathione, vitamins $\mathrm{E}$ and $\mathrm{C}$, uric acid, ceruloplasmin, and ferritin, as well as enzymatic antioxidants like CAT, SOD, and GPX (Wang,2011). Changes in these antioxidants can impact the body's redox equilibrium

Changes in the oxidant and antioxidant systems occur as a result of thyroid diseases. Thyroid hormones have a considerable influence on oxidative stress, according to evidence from in vitro and in vivo investigations (Birben et al.,2012).
Carbimzole is an antithyroid medication that is commonly used to patients with hyperthyroidism (Kota et al., 2013). Carbimazole has an active metabolite called methimazole that prevents the thyroid's peroxidase enzyme from coupling and tyrosine iodination, resulting in a decrease in T3 and T4 synthesis (Jasim et al., 2017).

Carbimazole and methimazole inhibited cytokine production and eliminated or reduced radical generation by complement-attacked thyroid cells. (Petrulea and colleagues, 2012).

\section{-Aim of the study}

The present study has been undertaken:

1. To assess the oxidative stress in patients with hyperthyroidism by measurement of malondialdehide (MDA) the end product of lipid peroxidation which is commonly used as indicator of oxidative stress.

2. To assess the antioxidant status of patients with hyperthyroidism

3. To evaluate the effect of carbimazole on the oxidative stress, antioxidant status in $\mathrm{HTH}$.

\section{METHOD}

The study had approval from Mosul College of medicine. Newly diagnosed Thirty patients whose ages between 15-70 years males and females, with hyperthyroid on Carbimazol will be enrolled in the study. Another thirty healthy subjects , were considered as a control group.

The patients were registered in the consultatory clinic of general surgery outpatient Department in AL-Jumhori teaching hospital and in private clinic,all investigations will e repeated after 2 months of treatments.

Pregnancy, smoking, consuming alcohol, steroid and non-steroid anti-inflammatory drugs and immunomodulators usage, having some diseases such as diabetes mellitus, renal failure, liver insufficiency, malignancy, infectious diseases, and other autoimmune diseases were excluded from our study.

The studied groups were subjected to measurement of weight and height to derive body mass index (BMI), according to the equation:

$\mathrm{BMI}=$ weight $(\mathrm{kg}) /$ height $\left(\mathrm{m}^{2}\right)$ (Leermarkers et al., 2000; Nuttall , 2015)

Serum MDA level, which is the consequence of lipid peroxidation and a marker of oxidative stress was measured using ELISA MDA kit. TAS was measured using Elabscience TAS kit .following the instructions included in the leaflet of the both kit. 


\section{Statistical analysis}

The collected data were compiled and analysed using percentages, mean, median, and Chi-square tests using SPSS version 20. P values of 0.05 were used as a cut-off point for the significance of the statistical test.

\section{RESULTS}

Table (1) shows the comparison between general characteristics of hyperthyroid patients and healthy control. There are no statistically differences between the two groups.
Table (2) shows the comparison of oxidative stress parameters between the hyperthyroid patients and healthy control at the beginning of study. There are statistically differences between the two groups.

Table (3) shows the comparison between before and after two months of therapy with carbimazole, on oxidative stress parameters. There were a significant differences (improvement) in MDA and T-AOC ( $\mathrm{P}$. Value = $0.001)$.

Table 1. Comparison of general characteristics between hyperthyroid patients and healthy control. Data expressed as Mean \pm SD.

\begin{tabular}{llll}
\hline Parameters & Patient group & Healthy group & P-value* $^{*}$ \\
\hline Age (years) & $39.30 \pm 14.10$ & $37.70 \pm 10.54$ & $\mathbf{0 . 6 2 1}$ \\
BMI $\left(\mathrm{kg} / \mathrm{m}^{2}\right)$ & $26.18 \pm 4.15$ & $26.93 \pm 4.03$ & $\mathbf{0 . 4 8 7}$ \\
\hline
\end{tabular}

* Independent T-test of two means was used.

Table 2. Comparison of oxidative stress parameters between the hyperthyroid patients and healthy control at the beginning of the study. Data expressed as Mean \pm SD.

\begin{tabular}{llll}
\hline Parameters & Patient group & Healthy group & P-value* $^{*}$ \\
\hline T-AOC $(\mathrm{U} / \mathrm{ml})$ & $6.72 \pm 3.08$ & $10.38 \pm 2.32$ & $\mathbf{0 . 0 0 1}$ \\
MDA $(\mathrm{ng} / \mathrm{ml})$ & $4.74 \pm 3.62$ & $1.83 \pm 0.47$ & $\mathbf{0 . 0 0 1}$ \\
\hline
\end{tabular}

* Independent T-test of two means was used

Table (3): comparison of mean serum level of MDA and T-AOC (before and after therapy). Data expressed as Mean \pm SD.

\begin{tabular}{lllll}
\hline Parameters & $\begin{array}{l}\text { Before } \\
(\mathbf{n}=\mathbf{3 0})\end{array}$ & $\begin{array}{l}\text { After } \\
(\mathbf{n = 3 0 )}\end{array}$ & \%lmprovement rate* & P-value $^{\star \star}$ \\
\hline MDA $(\mathrm{nmol} / \mathrm{ml})$ & $4.75 \pm 3.62$ & $2.51 \pm 1.99$ & $47.0 \%$ & $\mathbf{0 . 0 0 1}$ \\
T-AOC $(\mathrm{U} / \mathrm{ml})$ & $6.72 \pm 3.09$ & $8.57 \pm 3.09$ & $-27.4 \%$ & $\mathbf{0 . 0 0 1}$ \\
\hline
\end{tabular}

*\% Improvement rate $=[($ before - after $) /$ Before $] \times 100$.

** Paired T-test of two means was used.

\section{DISCUSSION}

Increased oxygen consumption, mitochondrial respiratory chain malfunction, increased intracellular ATP consumption, and increased reactive oxygen species (ROS) generation are all linked to hyperthyroidism (Marcocci et al., 2012). Despite the fact that many research have described the many biochemical parameters in thyroid gland malfunction, oxidative stress in thyroid hormones has received little attention.

However, there are many disagreements over the findings of numerous research on the role of thyroxine in oxidative stress and its effect on antioxidant enzymes (Das et al., 2020).

The oxidative stress in hyperthyroid individuals was assessed by measuring plasma levels of a lipid peroxidation byproduct, malondialdehyde (MDA), the most generally used oxidative stress indicator, and the plasma antioxidant state was assessed by measuring total antioxidant capacity (T-AOC). A control group of 30 people who appeared to be in good health was preserved for comparison of oxidative stress indicators.

The groups were matched in terms of number, age, and body mass index (BMI), as evidenced by the lack of statistically significant variations between the groups tested (table) (1). This matching of patient groups by number, age, and BMI may eliminate the impact of these variables on the study's outcomes. In the majority of other experiments in the antioxidant sector, the interference of age, number, and BMl factors with clinical trial outcomes was removed (Besler and Comoglu, 2003).

T-AOC testing is superior to testing individual antioxidant chemicals because it represents the body's total antioxidant capacity and provides a full picture of endogenous and exogenous 
capacity to combat and stop underlying oxidative damage. As a result, measuring total antioxidant capacity in the plasma may provide a more exact indicator of the link between antioxidants and disease (Hadzovic-Dzuvo et al., 2011).

Oxidative stress, which is defined as an increase in the concentration of reactive oxygen species (ROS), has been linked to a variety of diseases. However, there is a scarcity of information on the oxidative status of hypothyroidism and hyperthyroidism (Joshi et al.,2018)

Serum MDA levels were observed to be greater in hyperthyroid patients than in the control group (4.74 $3.62 \mathrm{nmol} / \mathrm{ml}$ and $1.830 .47 \mathrm{nmol} / \mathrm{ml}$, respectively) in this investigation. 0.001 is the $P$ value. MDA levels that were abnormally high indicate that oxidative stress was elevated in these patients.

Previous research has yielded mixed findings, however Venditti et al. (1997) found that MDA levels in hyperthyroid rats are significantly higher. It was shown in other investigations that the products of lipid peroxidation were reduced (Bozhko et al.,1990; Faure et al., 1991).

In hyperthyroid female patients, however, Fernandez et al., 1985, and Dumitriu et al., 1986, detected substantial lipid peroxidation products. Similarly, lipid peroxidation was observed to be higher in hyperthyroid female patients by langalenko et al., 1991. These findings were consistent with those seen in this investigation.

The findings of this study correspond with those of Olia et al., 2019, who reported that levels of malondialdehyde were higher in patients with hyperthyroidism and total antioxidant capacity was lower than in the control group. These results suggest that the thyroid gland is involved in the creation of oxidative stress in disease states.

$\mathrm{T}$-AOC concentrations in HT were lower than in the control group $(6.723 .08(\mathrm{U} / \mathrm{ml})$ and 10.38 $2.32(\mathrm{U} / \mathrm{ml})$, respectively, in this investigation. 0.001 is the P-value.

Our findings are consistent with those of some prior research comparing TAS and individual antioxidant enzyme concentrations in HT patients.

Patients with hyperthyroidism had lower antioxidant activity, according to Erdamar et al., 2008. MDA levels were higher in HTH patients when compared to the control group, and there were no significant differences between the two groups in terms of antioxidant enzymes (reduced glutathione (GSH), catalase (CAT), and superoxide dismutase) when Abd El-Hafes and El-Degheid (2008) measured MDA and individual antioxidant enzymes in HTH patients (SOD).

Korkmaz et al., 2015 looked at the Oxidative Stress Index (OSI) and Total Oxidative Stress (TOS) levels in patients with GD and HT, and found that both were significantly higher than the control group.

In a study published in 2019, Kocak et al. looked at TOS and OSI as oxidant markers and TAS as an antioxidant marker in patients with gravis disease. They found that TOS and OSI levels were greater and TAS was lower in the pretreatment GD group compared to the healthy control group.

Al-Jorani et al., 2021, examined antioxidant enzyme (Glutathione peroxidase) and blood selenium levels to assess antioxidant status. When compared to controls, the glutathione peroxidase activity and selenium levels in hyperthyroid individuals were found to be significantly lower. Hyperthyroidism is a hypermetabolic state characterized by increased oxygen consumption, increased reactive oxygen species generation, and, as a result, significant alterations in antioxidative variables. In patients with hyperthyroidism, a defective anti-oxidative factor causes the formation and presence of oxidative stress (Babu et al., 2011).

After two months of carbimazole medication. There were extremely significant differences (improvement) in MDA from 4.75 3.62 to 2.511 .99 $(\mathrm{nmol} / \mathrm{ml})$, with a $47.0 \%$ improvement rate, and in T-AOC from 6.723 .09 to $8.573 .09(\mathrm{U} / \mathrm{ml})$, with a $27.4 \%$ improvement rate $(P$. Value $=0.001)$.

\section{CONCLUSIONS}

Oxidative stress was enhanced in HTH patients as shown by a significant increased in MDA levels and decreasd in T-AOC compared with control group. Also treatment with the Carbimazole medicine resulted in a considerable reduction in MDA levels in the blood and a non-significant improvement in T-AOC.

\section{ETHICAL CONSIDERATIONS COMPLIANCE WITH ETHICAL GUIDELINES}

An administrative agreement was obtained from College of Medicine, University of Mosul, Iraq. The participants were informed about the research's purpose and ensured anonymity and confidentiality of the information. A written informed, voluntary participation consent was obtained from each participant.

\section{FUNDING}

This research did not receive any grant from funding agencies in the public, commercial, or non-profit sectors.

\section{AUTHOR'S CONTRIBUTIONS}

Study concept; Writing the original draft;D ata collection; Data analysis and Reviewing the final edition by the author.

DISCLOSURE STATEMENT: The authors report no conflict of interest.

\section{ACKNOWLEDGEMENTS}

We thank the anonymous referees for their useful suggestions. 


\section{REFERENCES}

Al-Jorani, Al-Sowdani, Saleh, (2021, March) LabMade Semi-Automated Microfluidic Flow Injection Spectrophotometric System for Determination of Nitrite in Natural Water. In Journal of Physics: Conference Series (Vol. 1818, No. 1, p. 012050). IOP Publishing

Babu, Jayaraaj, Prabhakar (2011) Effect of Abnormal thyroid hormone changes in lipid peroxidation and Antioxidant imbalance in Hypothyroid and Hyperthyroid patients. Int J Biol Med Res, 2(4), 1122-1126

Birben $E$, Sahiner $U$ M, Sackesen $C$, Erzurum $S$, Kalayci $O$ (2012) Oxidative stress and antioxidant defense. World Allergy Organization Journal, 5(1), 9-19

Besler and Çomog`lu (2003) Lipoprotein oxidation, plasma total antioxidant capacity and homocysteine level in patients with multiple sclerosis. Nutritional neuroscience, 6(3), 189-196. Bozhko, Gorodetskaia, Solodkov (1990) Restriction of stress-induced activation of lipid peroxidation by small doses of thyroid hormones. Biulleten'eksperimental'noi biologii i meditsiny, 109(6), 539-541.

Carrasco N (2005) Thyroid iodine transport. The thyroid, a fundamental and clinical text. Philadelphia: Lippincott Williams \& Wilkins, 37-52. Costilla M, Macri Delbono R, Klecha A, Cremaschi G A, \& Barreiro Arcos M L (2019) Oxidative stress produced by hyperthyroidism status induces the antioxidant enzyme transcription through the activation of the Nrf-2 factor in lymphoid tissues of Balb/c mice. Oxidative medicine and cellular longevity.

Das B, Samanta S, Rani R, Saxena S, Saxena I, Vanishree B J (2020) A study of oxidative stress, selected antioxidant enzymes, and total antioxidant activity in hypothyroid, hyperthyroid, and euthyroid. International Journal, 10.

Dumitriu, Bartoc, Ursu, Purice, \& Ionescu, (1988) Significance of high levels of serum malonyl dialdehyde (MDA) and ceruloplasmin (CP) in hyper-and hypothyroidism. Endocrinologie, 26(1), 35-38.

El-Hafez, El-Degheidy (2008). OXIDANTANTIOXIDANT STATUS IN PATIENTS WITH HYPERTHYROIDISM: EFFECT OF ANTITHYROID TREATMENT. Mansoura Medical Journal, 37(2), 395-411.

Erdamar H, Demirci H, Yaman H(2008) The effect of hypothyroidism, hyperthyroidism, and their treatment on parameters of oxidative stress and antioxidant status, Clin Chem Lab Med.;46(1):1004- 1010

Fauré, Lissi, Videla (1991) Evaluation of the antioxidant properties of thyroid hormones and propylthiouracil in the brain-homogenate autoxidation system and in the free radicalmediated oxidation of erythrocyte membranes. Chemico-biological interactions, 77(2), 173-185.

FERNANDEZ, BARRIENTOS, KIPREOS, VALENZUELA, \& VIDELA (1985) Superoxide radical generation, NADPH oxidase activity, and cytochrome P-450 content of rat liver microsomal fractions in an experimental hyperthyroid state: relation to lipid peroxidation. Endocrinology, 117(2), 496-501.

Hadžović-Džuvo, Lepara, Valjevac, Avdagić, Hasić, Kiseljaković, et al., (2011) Serum total antioxidant capacity in patients with multiple sclerosis. Bosnian Journal of Basic Medical Sciences, 11(1), 33.

langolenko, Okorokov, (1991) Blood levels of medium molecular weight peptides and lipid peroxidation activity in the differential diagnosis of diffuse toxic goiter. Problemy endokrinologii, 37(1), 10-12.

Jasim W K (2017) Protective effects of dehydroepiandrosterone (DHEA) against Carbimazol-induced toxicity in male mice. J. int. Sci Pharm. 281-277,(3)8.

Joshi K and Zacharin M (2018) Hyperthyroidism in an infant of a mother with autoimmune hypothyroidism with positive TSH receptor antibodies. Journal of Pediatric Endocrinology and Metabolism, 31(5), 577-580.

Kirkwood B R (1988) Essentials of Medical Statistics (Blackwell, Oxford, scientific puplication, Oxford; 43-56.

Korkmaz, Tabur, Ozkaya, Oguz, Aksoy Akarsu (2015) Serum prolidase levels in Graves' disease without ophthalmopathy and its association with oxidative status. Journal of endocrinological investigation, 38(11), 1167-1173.

Kocak, Akarsu, Korkmaz, Taysi (2019) THE EFFECT OF ANTITHYROID DRUGS ON OSTEOPONTIN AND OXIDATIVE STRESS IN GRAVES'DISEASE. Acta Endocrinologica (Bucharest), 15(2), 221.

Kota S K, Meher L K, Kota S K, Jammula S, Modi K D (2013) Carbimazole-induced cholestatic hepatitis in Graves' disease. Indian journal of Endocrinology and metabolism, 17(2), 326.

Leermakers EA, Dunn AL, and Blair SN (2000) Exercise management of obesity. The Medical clinics of North America; 84(2), 419440.

Mancini A, Di Segni C, Raimondo S, Olivieri G, Silvestrini A, Meucci E, e al (2016) Thyroid 
hormones, oxidative stress, and inflammation. Mediators of inflammation.

Marcocci C, Leo M, Altea M A (2012) Oxidative stress in Graves' disease. European Thyroid Journal, 1(2), 80-87.

Nuttall FQ (2015) Body Mass Index: Obesity, BMI, and Health: A Critical Review. Nutr Today; 50(3):117-128.

Olia B H, Khadem Ansari M H, Rasmi Y, Hasanzadeh-Moghadam M (2019) Evaluation of Malondialdehyde Levels and Total Antioxidant Capacity in Patients with Hyperthyroidism. international Journal of Research in Applied and Basic Medical Sciences 2019; 5(2):121-127

Petrulea M, Muresan A, Duncea I (2012) Oxidative stress and antioxidant status in hypo-and hyperthyroidism. The Antioxidant Enzyme, 197236.

Storz $\mathrm{P}(2005)$ Reactive oxygen species in tumor progression. Front Biosci.;10:1881- 1896.

Venditti, Balestrieri, Di Meo, De Leo, (1997) Effect of thyroid state on lipid peroxidation, antioxidant defences, and susceptibility to oxidative stress in rat tissues. Journal of Endocrinology, 155, 151157.

Wang $\mathrm{D}$, Feng JF, Zeng $\mathrm{P}$, Yang $\mathrm{YH}$, Luo J, Yang YW(2011) Total oxidant/antioxidant status in sera of patients with thyroid cancers. Endocr Relat Cancer.;18: 773-782. 